\title{
Timing and frequency of bowel activity in patients ingesting sodium picosulphate/magnesium citrate and adjuvant bisacodyl for colon cleansing before colonoscopy
}

\author{
Stephen Vanner MSc MD, Lawrence C Hookey BSc MD
}

\begin{abstract}
S Vanner, LC Hookey. Timing and frequency of bowel activity in patients ingesting sodium picosulphate/magnesium citrate and adjuvant bisacodyl for colon cleansing before colonoscopy. Can J Gastroenterol 2011;25(12):663-666.
\end{abstract}

BACKGROUND: Despite the wealth of research investigating bowel cleansing efficacy, there are very little data on the timing or frequency of bowel movements after each agent is ingested.

OBJECTIVE: To examine the effect of each component of a three-day combined sodium picosulphate/magnesium citrate (PSLX) and bisacodyl regimen on the timing and frequency of bowel activity in patients undergoing colonoscopy.

METHODS: Outpatients booked for colonoscopy were asked to complete a diary of their bowel preparation that tracked the timing of bowel movements. Bowel preparation quality was assessed using the Ottawa Bowel Preparation Scale. Bowel activity was compared with baseline and correlated with colon cleansing. Subgroup analysis was performed examining the effect of timing of the procedure and splitdose regimens.

RESULTS: One hundred patients undergoing colon cleansing received bisacodyl $10 \mathrm{mg}$ at 17:00 three days and two days before the day of colonoscopy. In one group, both sachets of PSLX were given the night before colonoscopy, while the second group, whose colonoscopies were scheduled after 11:00, ingested one sachet the night before and the second sachet at 06:00 on the day of colonoscopy. Patients had a mean of 1.7 bowel movements per day in the seven days before starting the cleansing regimen. Both doses of bisacodyl tablets resulted in a significant increase in the mean number of bowel movements compared with baseline (3.3/day first dose; 3.8/day second dose $[\mathrm{P}=0.03$ and 0.001 , respectively]). Each dose of PSLX also resulted in a significant increase in bowel movement frequency compared with baseline, with means of $4.4,6.3$ and 4.5 bowel movements after each dose. The mean time to the final bowel movement following the second sachet of PSLX was $8.9 \mathrm{~h}$ when taken the night before, and $3.9 \mathrm{~h}$ when taken the morning of the procedure. Bowel preparation quality significantly correlated with bowel frequency when total bowel movements were considered and when only the effects of bisacodyl were accounted for ( $\mathrm{P}<0.01$ for each).

DISCUSSION: These data demonstrate that the addition of bisacodyl before PSLX ingestion has a significant additive effect on bowel frequency and correlates with bowel cleansing quality. The timing of the resulting bowel movements have practical implications for sleep and travel times to endoscopy suites.

Key Words: Bisacodyl; Colon cleansing; Magnesium sulfate; Sodium picosulphate

\footnotetext{
There is growing evidence that the efficacy of existing colon cleansing regimens can be significantly enhanced by adjusting the timing of the dosing of the preparation and combining the use of stimulant laxatives (1-5). For example, several studies suggest that the time interval from the final dose of a purgative to the start of the colonoscopy is
}

\begin{abstract}
Le moment et la fréquence de l'activité intestinale chez des patients qui ingèrent $\mathrm{du}$ picosulfate sodique et du citrate de magnésium ainsi qu'un adjuvant de bisacodyl pour nettoyer le côlon avant une coloscopie
\end{abstract}

HISTORIQUE : Malgré la pléthore de recherches sur l'efficacité du net-
toyage intestinal, il existe très peu de données sur le moment et la fréquence des mouvements intestinaux après l'ingestion de chaque agent.

OBJECTIF : Examiner l'effet de chaque composante d'une polythérapie de trois jours au picosulfate sodique et au citrate de magnésium (PSLX) associée au bisacodyl sur le moment et la fréquence de l'activité intestinale chez des patients qui subissent une coloscopie.

MÉTHODOLOGIE : Des patients ambulatoires qui avaient rendez-vous en coloscopie ont été invités à rédiger un journal de leur préparation intestinale dans lequel ils devaient préciser le moment de leurs mouvements intestinaux. Les chercheurs ont évalué la qualité de la préparation intestinale d'après l'échelle de préparation intestinale d'Ottawa. Ils ont comparé l'activité intestinale aux valeurs de base et l'ont corrélée avec le nettoyage du côlon. Ils ont procédé à une analyse de sous-groupe portant sur l'effet du moment de l'intervention et sur des posologies à doses fractionnées.

RÉSULTATS : Cent patients qui devaient subir un nettoyage du côlon ont reçu $10 \mathrm{mg}$ de bisacodylà $17 \mathrm{~h}$ trois jours, puis deux jours avant la coloscopie. Dans un groupe, les deux sachets de PSLX ont été remis le soir précédant la coloscopie, tandis que les patients de l'autre groupe, dont les rendez-vous de coloscopie étaient prévus après $11 \mathrm{~h}$, ont ingéré le premier sachet le soir précédant la coloscopie et le deuxième sachet à $6 \mathrm{~h}$ le jour de la coloscopie. Les patients avaient une moyenne de 1,7 mouvement intestinal par jour dans les sept jours précédant la posologie de nettoyage. Les deux doses de bisacodyl en comprimé ont suscité une augmentation significative du nombre moyen de mouvements intestinaux par rapport aux valeurs de départ (3,3/jour après la première dose; $3,8 /$ jour après la deuxième dose $[\mathrm{P}=0,03$ et 0,001 , respectivement $]$ ). Chaque dose de PSLX a également entraîné une augmentation significative de la fréquence des mouvements intestinaux par rapport aux valeurs de départ, avec des moyennes de $4,4,6,3$ et 4,5 mouvements intestinaux après chaque dose. Le délai moyen avant le dernier mouvement intestinal suivant le deuxième sachet de PSLX était de 8,9 h lorsqu'il était consommé la nuit précédant l'intervention, et de 3,9 heures lorsqu'il était consommé le matin même. La qualité de la préparation intestinale avait une corrélation significative avec la fréquence intestinale lorsqu'on tenait compte du total des mouvements intestinaux et lorsqu'on se limitait aux effets du bisacodyl ( $\mathrm{P}<0,01$ dans chacun des cas). EXPOSÉ : Ces données démontrent que l'ajout de bisacodyl avant l'ingestion de PSLX a un effet significatif sur la fréquence des mouvements intestinaux et est corrélé avec la qualité du nettoyage intestinal. Le moment des mouvements intestinaux qui s'ensuivent a des conséquences pratiques sur le sommeil et la durée du déplacement vers le bloc d'endoscopie.

very important to the efficacy of cleansing $(4,6-9)$. These studies suggest that intervals of greater than $6 \mathrm{~h}$ to $12 \mathrm{~h}$ from the administration of the final dose of the cleansing agent, regardless of the preparation used, results in inferior cleansing. Thus, giving the final dose of a cleansing agent within approximately $6 \mathrm{~h}$ of the colonoscopy evaluation appears

Gastrointestinal Diseases Research Unit, Kingston General Hospital, Queen's University, Kingston, Ontario

Correspondence: Dr Lawrence C Hookey, Hotel Dieu Hospital, 166 Brock Street, Kingston, Ontario K7L 5G2. Telephone 613-544-3310,

fax613-544-3114, e-mail hookeyl@hdh.kari.net

Received for publication April 7, 2011. Accepted May 25, 2011 


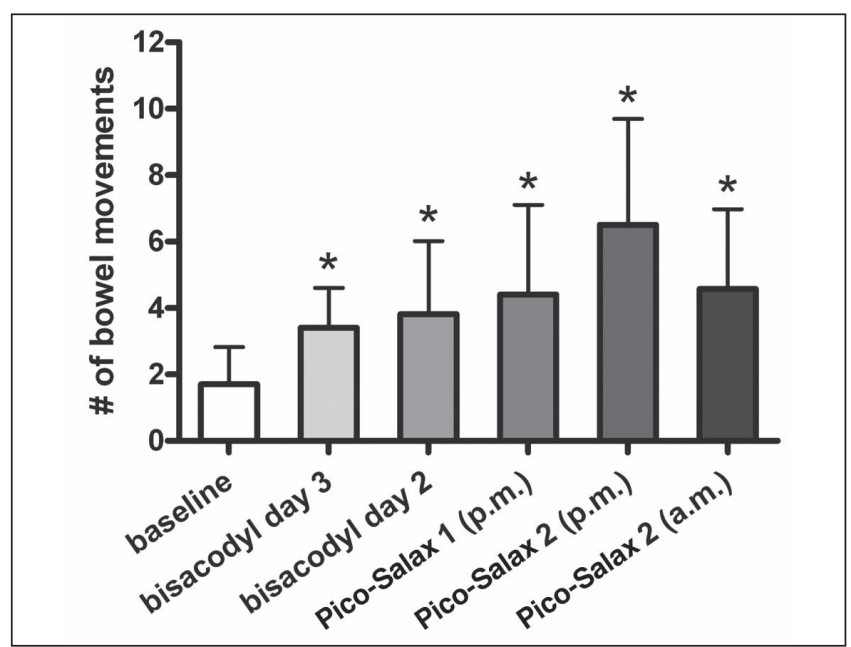

Figure 1) Mean number of bowel movements stimulated by each component of the colon cleansing regimen compared with baseline. Pico-Salax, Ferring Pharmaceuticals Inc, Canada

to provide superior colon cleansing. In addition to the timing factor, the use of stimulant laxatives, in combination with cleansing regimens, can also enhance the quality of the colon cleansing - at least in some studies. This has been most evident for the large-volume polyethylene glycol solutions (PEG) in which the ingestion of a stimulant laxative within $1 \mathrm{~h}$ to $2 \mathrm{~h}$ of taking the PEG solution enabled the volume of PEG preparations to be reduced without having a major effect on efficacy (10). More recently, we have shown that bisacodyl tablets (a stimulant laxative) given for two days before colon cleansing with sodium picosusulphate/magnesium citrate (Pico-Salax [PSLX], Ferring Pharmaceuticals Inc, Canada) also enhances the degree of colon cleansing (11). PSLX is a combination of sodium picosulphate (a stimulant laxative) and magnesium citrate (an osmotic laxative). The use of this regimen has subsequently become widespread in Canada.

To better understand and fully maximize the impact of components of a colon cleansing regimen, either through adjustment of timing or the addition of a stimulant laxative, it is essential to accurately evaluate the impact of these interventions. Understanding the colonic response to purgatives also has practical implications concerning sleep and travel time to the endoscopy suite. Surprisingly, little data are available in this regard with any of the available bowel preparations, including PSLX. Although Linden and Waye (12) examined the effects of sodium phosphate, including influence on transit and sleep, this agent has subsequently been withdrawn from the market. Hence, we undertook the current study in an effort to better document and understand the exact effects of the agents of PSLX combined with bisacodyl tablets over a three-day cleansing period.

\section{METHODS}

Patients were recruited from the outpatient gastroenterology clinics at Hotel Dieu Hospital (Kingston, Ontario). All of the patients' colonoscopies were ordered by their attending gastroenterologist for routine clinical indications. Exclusion criteria included the following: congestive heart failure; renal insufficiency (estimated glomerular filtration rate $<90 \mathrm{~mL} / \mathrm{min}$ ); ileus or bowel obstruction; previous colorectal surgery; ascites; active inflammatory bowel disease; and recent (less than six months) myocardial infarction or unstable angina. All patients provided informed consent for the procedure; the study was approved by the Queen's University Health Sciences and Affiliated Teaching Hospitals Research Ethics Board (Kingston, Ontario).

All patients took PSLX combined with bisacodyl for colon cleansing. They were instructed to take one $10 \mathrm{mg}$ tablet of bisacodyl at 18:00 for two consecutive nights before taking the PSLX (days three and two precolonoscopy). Patients were instructed to avoid seeds and high-fibre products for five days before examination followed by a clear fluid diet the day before colonoscopy. Patients were encouraged to drink $4 \mathrm{~L}$ of a carbohydrate electrolyte sports drink solution (Gatorade [QTG, Canada] or equivalent) during the day of clear fluids and continue this up until the time they left their residence for their procedure (13). The timing of PSLX ingestion was adjusted according to the scheduled time of colonoscopy.

Traditional dosing regimen: Patients whose colonoscopy was scheduled before 11:00 were asked to take one dose of PSLX at 17:00 and the second dose at 22:00 the evening before colonoscopy.

Spilt-dosing regimen: Patients whose colonoscopies were scheduled after 11:00 were asked to take one dose at 19:00 the evening before colonoscopy and the second dose at 06:00 on the day of colonoscopy.

These two groups were analyzed separately because, when taken in the evening, the second dose of PSLX would potentially alter or confound the effects of the first dose.

In addition to these instructions, patients were given a diary to record the study data. This included their average bowel movement frequency in the week before starting the bowel preparation, the time at which each preparation medication was taken, the time of each subsequent bowel movement, and the total amount of sports drink and overall fluids consumed starting the day before colonoscopy.

Patients underwent colonoscopy by one of eight gastroenterologists who then rated the quality of the bowel preparation using the Ottawa Bowel Preparation Scale score (14) and the Aronchick score (15). These gastroenterologists had undergone training to ensure consistency when evaluating the quality of colon cleansing (16).

\section{Statistics}

Descriptive statistics with means and SD, or medians with ranges are used to describe data, depending on the distribution. The mean number of bowel movements produced by each component of the cleansing regimen was compared with baseline using paired $t$ tests, with the patients serving as their own controls. Subgroup analysis was planned for comparison based on whether the patients took both doses of PSLX the evening before colonoscopy or one in the evening and one in the morning of the colonoscopy. Analysis was performed using the $\chi^{2}$ test, Mann Whitney test or Student's $t$ test, as appropriate. Pearson correlation coefficients $(r)$ were used to further assess whether the number of bowel movements from both doses of bisacodyl and the entire preparation related to the quality of the bowel cleansing assessed by the Ottawa Bowel Preparation Scale. One hundred patients were enrolled to allow for adequate distribution of responses and description of mechanism results. Subgroup analyses were performed as exploratory tests; however, the study was not necessarily powered to assess these questions directly. The data are presented as mean \pm SD.

\section{RESULTS}

One hundred patients ( 42 men) with a mean age of 60.2 years (range 19 to 82 years) participated in the present study. Only four patients met the constipation criteria of $<3$ spontaneous bowel movements per week. Patients ingested a mean of $4.9 \mathrm{~L}$ (range $1 \mathrm{~L}$ to $17 \mathrm{~L}$ ) of clear fluids including a mean of $1.5 \mathrm{~L}$ (range $0 \mathrm{~L}$ to $5.25 \mathrm{~L}$ ) of sports drink the day before colonoscopy. Five patients underwent incomplete colonoscopies: four due to abdominal discomfort and one due to a poor preparation and a sigmoid stricture, which was subsequently surgically resected.

Comparison of the effect on the frequency of bowel movements for each purgative component

The mean baseline number of bowel movements per day in the seven days before commencing the cleansing regimen was $1.7 \pm 1.1$. Compared with this baseline number of bowel movements per day, the addition of bisacodyl resulted in a significant increase in the number of bowel movements on each day it was taken, with means of $3.3 \pm 2$ and $3.8 \pm 2.2$ bowel movements on days 3 and 2 precolonoscopy, respectively $(\mathrm{P}<0.05)$ (Figure 1). Patients experienced a significantly greater number of bowel movements with each dose of PSLX when compared with baseline. The first dose resulted in a mean of $4.4 \pm 2.7$ bowel movements. 
TABLE 1

Effects in time and total bowel activity of each component of the sodium picosulphate/magnesium citrate (PSLX) and bisacodyl bowel preparation regimen

\begin{tabular}{lccc}
\hline & \multicolumn{2}{c}{ Time, $\mathbf{h}$} & \multicolumn{2}{c}{ Total number of } \\
bowel movements
\end{tabular}

Data presented as mean \pm SD
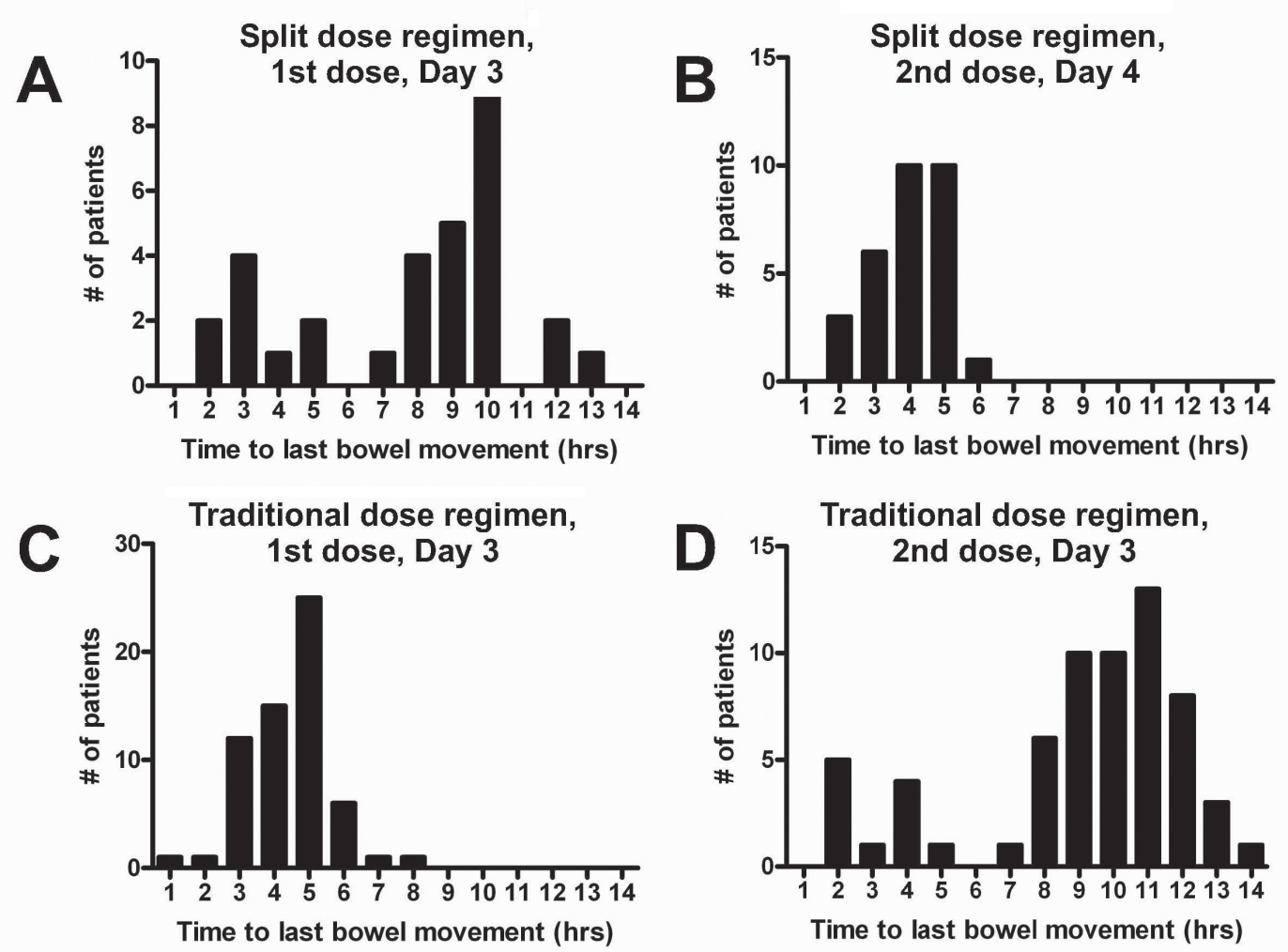

Figure 2) A to D Range of time from ingestion of the first and second dose of sodium picosusulphate/magnesium citrate (Pico-Salax [Ferring Pharmaceuticals Inc, Canada]) to the final bowel movement, demonstrated by dosing regimen used. Note that the effects of the first dose in the traditional regimen may be truncated by the ingestion of the second dose. Likewise, the effects of the second dose in the split-dose regimen may be truncated by the initiation of the procedure

Those taking a second dose the same night had a mean of $6.3 \pm 3.0$ bowel movements, with those taking morning doses having $4.5 \pm 2.4$ bowel movements after each dose.

Comparison of the timing effect on bowel movements for each purgative component

Bisacodyl: The average time to the first bowel movement following the first dose of bisacodyl was $8.9 \pm 5 \mathrm{~h}$, and the mean time to the final bowel movement was $16.5 \pm 5.1 \mathrm{~h}$. The effect of the second bisacodyl dose exhibited a similar range (Table 1 ).

Evening PSLX dosing ( $n=68)$ : The first dose of PSLX produced the first bowel movement at a mean of $1.5 \pm 1 \mathrm{~h}$ (range $0 \mathrm{~h}$ to $4 \mathrm{~h}$ ) after ingestion. The final bowel movement occurred at a mean of $5.4 \pm 2.5 \mathrm{~h}$ (range $2 \mathrm{~h}$ to $14 \mathrm{~h}$ ).

Split-dose PSLX $(n=32)$ : The first dose produced the first bowel movement at a mean of $1.3 \pm 1.3 \mathrm{~h}$ (range $0 \mathrm{~h}$ to $9 \mathrm{~h}$ ) after ingestion, with the final bowel movement occurring at an average of $9.6 \pm 4.6 \mathrm{~h}$ (range $2 \mathrm{~h}$ to $13 \mathrm{~h}$ ) after ingestion (Table 1). After the morning dose of PSLX, the first bowel motion occurred at $0.9 \pm 0.8 \mathrm{~h}$ (range $0 \mathrm{~h}$ to $4 \mathrm{~h}$ ), and the final at a mean of $3.9 \pm 1 \mathrm{~h}$ (range $2 \mathrm{~h}$ to $6 \mathrm{~h}$ ) after ingesting the medication (Figure 2).
Comparison of the efficacy of colon cleansing in patients receiving PSLX the night before with those receiving a split dose

Previous studies examining the use of PSLX the night before colonoscopy (11) showed that the efficacy of colon cleansing was significantly lower in patients who underwent colonoscopy after 11:00. In the current study, patients who were booked for colonoscopy after 11:00 $(n=32)$ were instructed to take their second dose of PSLX at 06:00 on the day of colonoscopy as opposed to the night before. In contrast to the previous findings, there was no difference in efficacy between the two groups, with total Ottawa Bowel Preparation Scale scores of $5.22 \pm 3.1$ and $5.03 \pm 2.8$ for the evening dosing and split dosing, respectively $(\mathrm{P}=0.77)$. Similarly, no significant differences were seen between the groups using the Aronchick score (Figure 3).

Relationship of bowel movement frequency and bowel cleansing quality

As the number of total bowel movements increased, the quality of the bowel cleansing, as indicated by a lower Ottawa Bowel Preparation Scale score, improved $(\mathrm{r}=0.481 ; \mathrm{P}<0.001)$. The quality of bowel cleansing also correlated with the total number of bowel movements produced by both doses of bisacodyl $(\mathrm{r}=0.315 ; \mathrm{P}=0.002)$. 


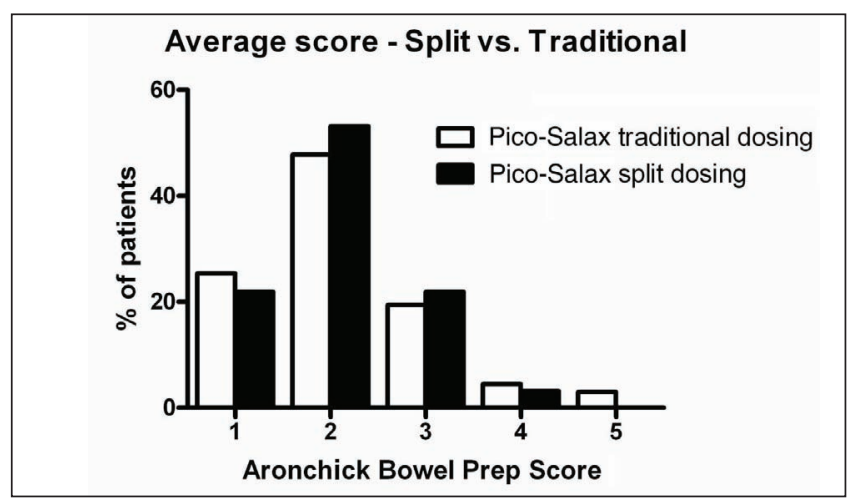

Figure 3) Aronchick bowel preparation (Prep) scores for patients receiving sodium picosusulphate/magnesium citrate (Pico-Salax [Ferring Pharmaceuticals Inc, Canada]) the night before or the split dose (ie, night before and morning of procedure). vs Versus

\section{DISCUSSION}

The present study was the first to record the effects of bisacodyl and PSLX on bowel movement timing and frequency when these agents were used for colon cleansing. These data have important implications for understanding the role of each component. Both the adjuvant stimulant laxative bisacodyl and the PSLX resulted in a significantly greater number of bowel movements compared with each patient's baseline. The true effect of the second dose in the split-dose group may have been partially underestimated due to the fact that patients possibly underwent their procedure before all bowel activity had ceased. Moreover, it demonstrated how the timing of these components could be optimized to improve patient satisfaction and maximize the quality of the bowel preparation before colonoscopy. For instance, given the average of approximately $8 \mathrm{~h}$ between bisacodyl ingestion and onset of action, the doses could be taken earlier in the day to avoid disruption of sleep during the night.

Our previous study had suggested that the addition of a stimulant laxative for two days before the ingestion of PSLX improved the quality of colon cleansing, but did not compromise patient tolerability of the preparation compared with those receiving PSLX alone (11). Although the mechanism of this effect was unclear, intuitively, we believed that it was the result of the additional laxative effect of the bisacodyl. The results of the current study document that bisacodyl

\section{REFERENCES}

1. Aoun E, Abdul-Baki H, Azar C, et al. A randomized single-blind trial of split-dose PEG-electrolyte solution without dietary restriction compared with whole dose PEG-electrolyte solution with dietary restriction for colonoscopy preparation. Gastrointest Endosc 2005;62:213-8.

2. El Sayed AM, Kanafani ZA, Mourad FH, et al. A randomized single-blind trial of whole versus split-dose polyethylene glycolelectrolyte solution for colonoscopy preparation. Gastrointest Endosc 2003;58:36-40.

3. Hookey LC, Vanner S. A review of current issues underlying colon cleansing before colonoscopy. Can J Gastroenterol 2007;21:105-11.

4. Rex DK, Vanner SJ. Colon cleansing before colonoscopy: Does oral sodium phosphate solution still make sense? Can J Gastroenterol 2009;23:210-4.

5. Rostom A, Jolicoeur E, Dube C, et al. A randomized prospective trial comparing different regimens of oral sodium phosphate and polyethylene glycol-based lavage solution in the preparation of patients for colonoscopy. Gastrointest Endosc 2006;64:544-52.

6. Chiu HM, Lin JT, Wang HP, Lee YC, Wu MS. The impact of colon preparation timing on colonoscopic detection of colorectal neoplasms - a prospective endoscopist-blinded randomized trial. Am J Gastroenterol 2006;101:2719-25.

7. Church JM. Effectiveness of polyethylene glycol antegrade gut lavage bowel preparation for colonoscopy - timing is the key! Dis Colon Rectum 1998;41:1223-5.

8. Kossi J, Krekela I, Patrikainen H, Vuorinen T, Luostarinen M, Laato M. The cleansing result of oral sodium phosphate is inversely correlated significantly increases the number of bowel movements over baseline and demonstrates that the average magnitude of this effect is approximately double that of the patients' baseline bowel habit. We also showed that the total number of bowel movements produced by bisacodyl significantly correlated with the quality of bowel cleansing, confirming the role of the adjuvant stimulant in the regimen. The findings also have implications for the timing of this ingestion, implying that taking the pills either in the afternoon or at bedtime may have the least impact on interfering with the patients' sleep. Patients may wish to take the medication even earlier in the day, although this may impact on other activities such as work.

Although patients were not asked directly about sleep or travel disturbances, our results regarding the timing of the final bowel movements following the ingestion of the second doses of PSLX also have important implications for sleep if taken the night before colonoscopy or for travelling to the endoscopy suite, particularly if it involves considerable distances. Our data suggest that the second dose taken the night before will likely interrupt patients' sleep for most of the night, but will have little impact on driving to the endoscopy suite on the day of the colonoscopy. For patients who take the second dose in the morning, it appears that at least $4 \mathrm{~h}$ should be recommended before travelling to the endoscopy suite because the mean time to final bowel movement after the second dose was $3.9 \mathrm{~h}$.

\section{SUMMARY}

The present study clarifies the contribution of individual components of the bisacodyl and PSLX colon-cleansing regimen, and supports the rationale for their combined use. Moreover, it demonstrates that greater understanding of the effects of each component can help to guide instruction in their use, which can enhance patient satisfaction and the efficacy of the preparation. Additional studies are needed to better understand individual patient variables such as constipation or medication use. Additional details regarding specific sleep and travel inconveniences would also serve to enable the design of an efficacious preparation that has the minimum impact on quality of life.

CONFLICTS OF INTEREST: Drs Vanner and Hookey have both received research funds and consulting fees from Ferring Canada in the past. This study however, was internally funded and investigator initiated, and Ferring Canada was not invovled in any way.

with time between the last administration and colonoscopy. Tech Coloproctol 2007;11:51-4.

9. Parra-Blanco A, Nicolas-Perez D, Gimeno-Garcia A, et al. The timing of bowel preparation before colonoscopy determines the quality of cleansing, and is a significant factor contributing to the detection of flat lesions: A randomized study. World J Gastroenterol 2006;12:6161-6.

10. DiPalma JA, Wolff BG, Meagher A, Cleveland M. Comparison of reduced volume versus four liters sulfate-free electrolyte lavage solutions for colonoscopy colon cleansing. Am J Gastroenterol 2003;98:2187-91.

11. Hookey LC, Vanner SJ. Pico-salax plus two-day bisacodyl is superior to pico-salax alone or oral sodium phosphate for colon cleansing before colonoscopy. Am J Gastroenterol 2009;104:703-9.

12. Linden TB, Waye JD. Sodium phosphate preparation for colonoscopy: Onset and duration of bowel activity. Gastrointest Endosc 1999;50:811-3.

13. Barclay RL, Depew WT, Vanner SJ. Carbohydrate-electrolyte rehydration protects against intravascular volume contraction during colonic cleansing with orally administered sodium phosphate. Gastrointest Endosc 2002;56:633-8.

14. Rostom A, Jolicoeur E. Validation of a new scale for the assessment of bowel preparation quality. Gastrointest Endosc 2004;59:482-6.

15. Aronchick CA, Lipshutz WH, Wright SH, Dufrayne F, Bergman G. Validation of an instrument to assess colon cleansing. Am J Gastroenterol 1999;94:2667. (Abst)

16. McKnight LC, Day AG, Hookey LC. A formal assessment of the need for teaching prior to the use of the Ottawa Bowel Preparation Scale. Am J Gastroenterol 2006;101:s508. 


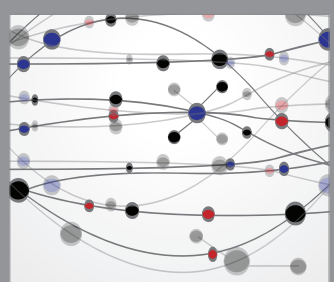

The Scientific World Journal
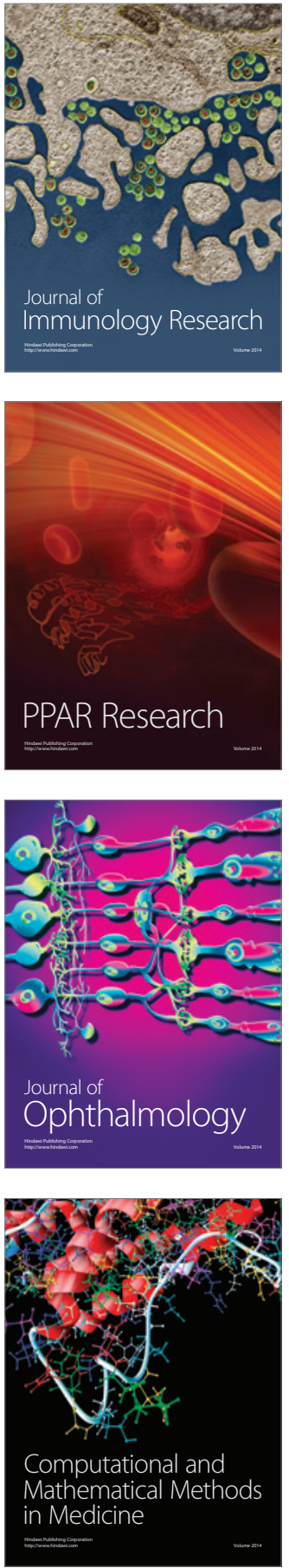

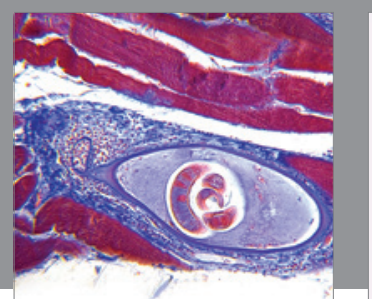

Gastroenterology Research and Practice

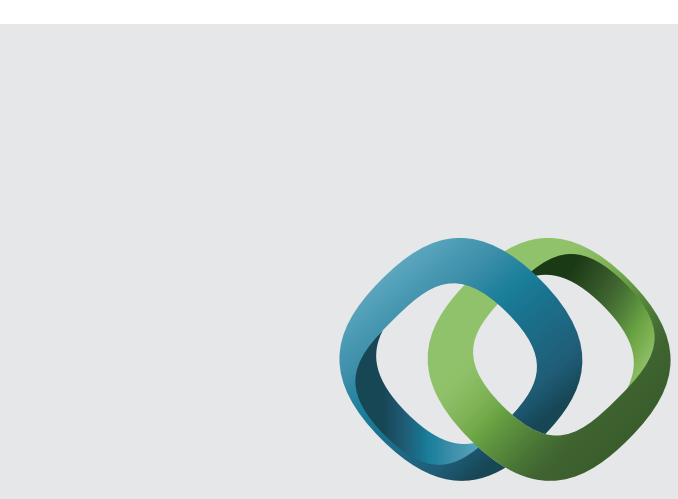

\section{Hindawi}

Submit your manuscripts at

http://www.hindawi.com
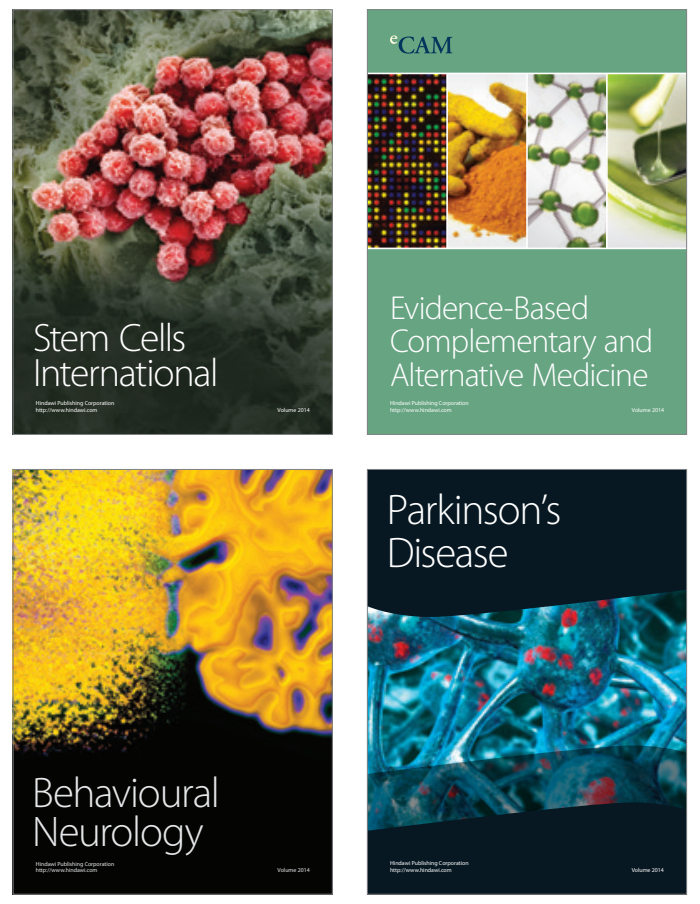
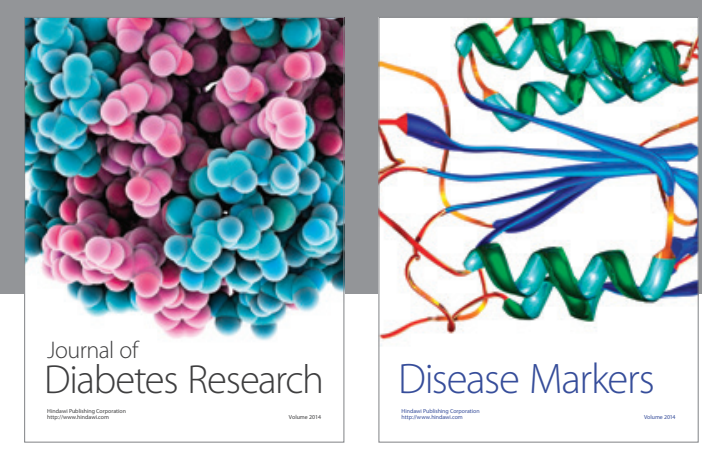

Disease Markers
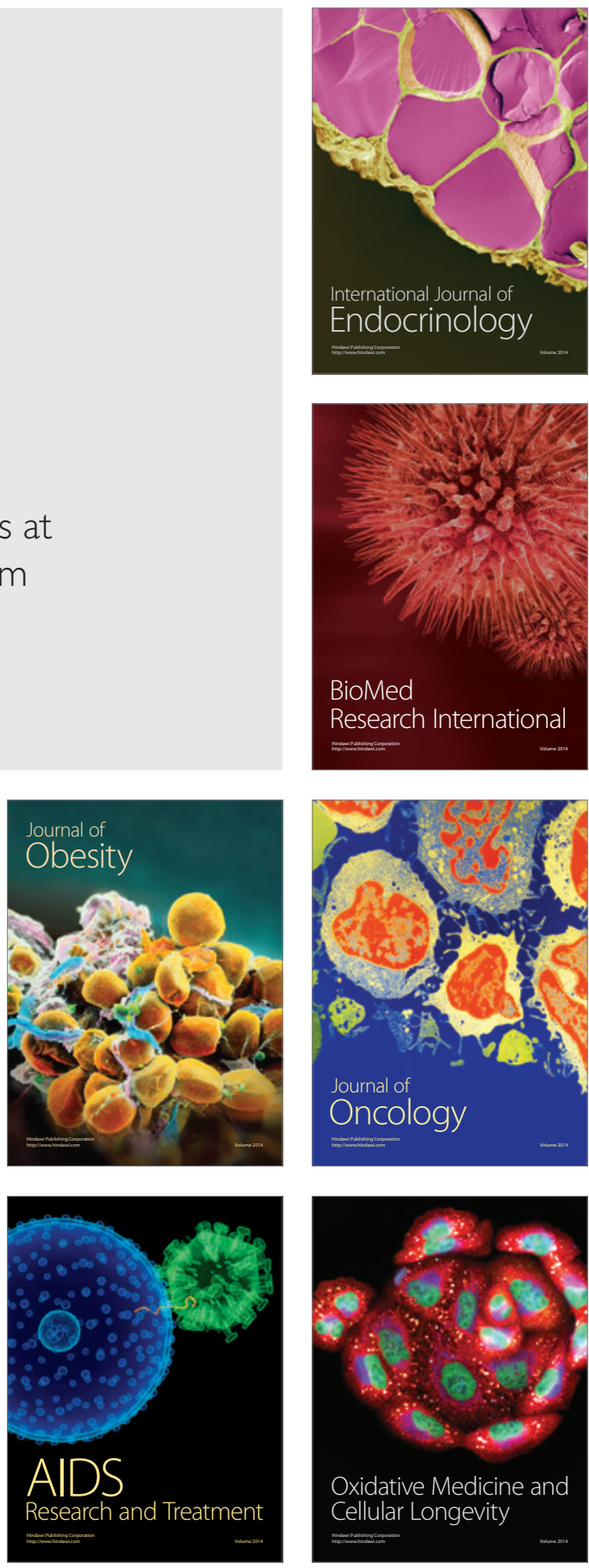